Brit. F. vener. Dis. (1968), 44, 67.

\title{
CHACKO-NAIR EGG-ENRICHED SELECTIVE MEDIUM IN THE DIAGNOSIS OF PATHOGENIC NEISSERIAE*
}

\author{
BY \\ C. W. CHACKO AND G. M. NAIR \\ Central V.D. Reference Laboratory, Institute of Venereology, \\ Madras Medical College, India
}

An egg-enriched medium made selective by the addition of Polymyxin B and Mycostatin, for the isolation of $N$. gonorrhoeae was described by Chacko and Nair (1966). The evaluation of this medium has since been extended to further cases of $N$. gonorrhoeae and also to $N$. meningitidis. The results indicate the usefulness of the Chacko-Nair medium, not only in the diagnosis of gonorrhoea, but also in the isolation of $N$. meningitidis in culture.

\section{Methods and Material \\ Preparation of the Medium}

The basal medium was prepared as follows: $100 \mathrm{~g}$. minced beef muscle free from fat were weighed into a 1,000-ml. Pyrex conical flask and $500 \mathrm{ml}$. distilled water were added and mixed with a Waring blender. $15 \mathrm{ml}$. $1 / \mathrm{N}$. $\mathrm{NaOH}$ were added and the mixture was brought to a temperature of 75 to $80^{\circ} \mathrm{C}$. for 5 minutes, preferably in a water bath. After cooling to $40^{\circ} \mathrm{C}$., $0.20 \mathrm{~g}$. Trypsin powder (1:250 Difco) was added and the mixture incubated at $37^{\circ} \mathrm{C}$. for 6 hours for digestion to occur; $0 \cdot 7$ $\mathrm{ml}$. glacial acetic acid was then added and the whole mixture was boiled for 10 minutes to arrest the digestion. It was then kept in a refrigerator overnight and filtered through gauze. Filtration was also carried out through filter paper to make it clear if found necessary.

$500 \mathrm{ml}$. of 1 per cent. sodium chloride (AR) were prepared in a separate $1,000-\mathrm{ml}$. flask and well mixed with the above filtrate. $1 \mathrm{~g}$. glucose and $5 \mathrm{~g}$. disodiummono-hydrogen phosphate (AR) were added and dissolved. The $\mathrm{pH}$ was adjusted to $7 \cdot 2-7 \cdot 4$, using a $\mathrm{pH}$ comparator and bromothymol blue as indicator. It was then distributed into $200 \mathrm{ml}$. quantities in conical flasks, $4 \mathrm{~g}$. basic agar (Difco) being added to each flask. The agar was dissolved in a boiling water bath and autoclaved at $10 \mathrm{lb}$. pressure for 30 minutes. This stock of basal medium was preserved at room temperature until it was used.

\footnotetext{
* Received for publication March 20, 1967
}

Just before use, $200 \mathrm{ml}$. of the basal medium were melted in a water bath and cooled to 55 to $50^{\circ} \mathrm{C}$.; Polymyxin B sulphate (Pfizer) and Mycostatin (SquibbNystatin) were added to give a concentration of 30 units each per $\mathrm{ml}$. of the medium and the contents were well mixed by rotating the flask.

\section{Enrichment of the Basal Medium}

Fresh chicken eggs bought from the market were used for enrichment. The shell was cleaned with soap and water and dried. Tincture of iodine was applied over the air-sac portion, and the iodine was removed with 70 per cent. alcohol. The shell was pierced at the middle of the air-sac end, using the pointed edge of a small pair of sterile scissors, and was cut off to a diameter of 1 to $1.5 \mathrm{~cm}$. A sterile nichrome-loop was introduced into the egg and the white and yolk well mixed by rotating the loop inside, holding the egg near a flame to avoid the possibility of aerial contamination. To each 200 $\mathrm{ml}$. of the melted basal medium in the flask kept at 55 to $50^{\circ} \mathrm{C}$., the contents of a hen's egg were added directly and homogenized well by rotating the flask on a flat surface. This gave an approximate concentration of 10 per cent. enrichment of the medium with whole egg contents and 25 units per ml. of Polymyxin B and of Mycostatin. The medium was poured into Petri dishes to a depth of about $4 \mathrm{~mm}$. and allowed to solidify at room temperature. Slopes of the medium were also made in test-tubes in the usual way. They were incubated at $37^{\circ} \mathrm{C}$. for 24 hours before use, to test for sterility.

\section{Evaluation}

The medium was evaluated by comparing the isolation of gonococci from material inoculated in parallel on the test medium and on Bacto G.C. medium base, enriched with Bacto haemoglobin and Supplement B of yeast concentrates of Difco origin, and made selective by including 25 units of each of Polymyxin B and Mycostatin per ml.

Specimens were obtained from the out-patients department of the Institute of Venereology, Government General Hospital, Madras. The epidemiological study of $N$.gonorrhoeae was conducted on specimens obtained from the above department and from the out-patients department of the Government Women and Children's Hospital, 
Madras. For the epidemiological study of $N$. meningitidis, specimens were obtained from the out-patients department of the Institute of Paediatrics of the Government General Hospital, Madras. vaginal, and cervical specimens from female patients were cultured for $N$. gonorrhoeae; nasopharyngeal swabs from the children were cultured for $N$. meningitidis. The material was inoculated directly on to the medium and was immediately incubated at $37^{\circ} \mathrm{C}$. in a candle jar for 24 hours.

The oxidase reaction was carried out by dropping a 1 per cent. aqueous solution of p-animo-dimethyl aniline on to suspected colonies. Those of gonococci and meningococci immediately turned pink, becoming maroon and finally "black" in a few minutes. The original smears obtained directly from the test material for gonococci and meningococci and smears from colonies were also stained by Gram's method.

Gram-negative diplococci with the characteristic mordirect smears and in those prepared from cultures were confirmed as being gonococci or meningococci by sugar fermentation reactions on pure cultures.

The study was carried out on a total of 1,262 specimens obtained from different sources. These included 678 Clinic of the Madras Institute of Venereology who were thought to have gonorrhoea on clinical grounds; parallel cultures were made on the two media with secretions from these cases. The remaining 584 specimens included material for an epidemiological study of 371 cases for gonococci and 213 cases for meningococci; material from these groups was inoculated only on the eggenriched medium.

\section{Results}

The results are analysed in Tables $\mathrm{I}$ to III.
Urethral secretions from male patients and urethral, phology of the Neisseria group of organisms seen in specimens from 370 males and 308 females attending the

Table I shows that, in 296 male cases of acute urethritis, in which intracellular Gram-negative diplococci resembling gonococci were demonstrated in direct smears, gonococci were cultured on the Chacko-Nair medium and Difco G.C. medium in 296 and 294 instances respectively. It was found that the Difco medium did not support the primary growth of two strains of gonococci from either the urethral discharge or urinary sediment from one patient, while both strains grew on the ChackoNair medium. However, sub-cultures of the two strains from the Chacko-Nair medium to the Difco medium adapted themselves to the latter. Thus the egg-enriched medium supported the growth of all the strains of gonococci from this group of patients.

In eight cases of urethritis in males, direct smears were negative, but gonococci were grown on both media. This seemed to confirm that the Gramstained smear method alone is not adequate for the diagnosis of male urethritis, and that there is a need for a very nutritive culture medium for the gonococcus, simpler and more conveniently available in practice than the conventional G.C. medium in use at present.

In 66 (18 per cent.) of the 370 cases of urethritis in males examined, gonococci could not be cultured on either of the two media or demonstrated in direct smears of the discharge. This may mean that the current laboratory methods of confirming clinical suspicion are not sensitive enough, or that these were not in fact cases of gonococcal urethritis. However, the finding of 304 (82 per cent.) positive cultures of the gonococcus in this random study of 370 cases of urethritis in males may be

TABLE I

PRIMARY CULTURE OF GONOCOCCUS IN EGG-ENRICHED MEDIUM COMPARED WITH DIFCO G.C. MEDIUM

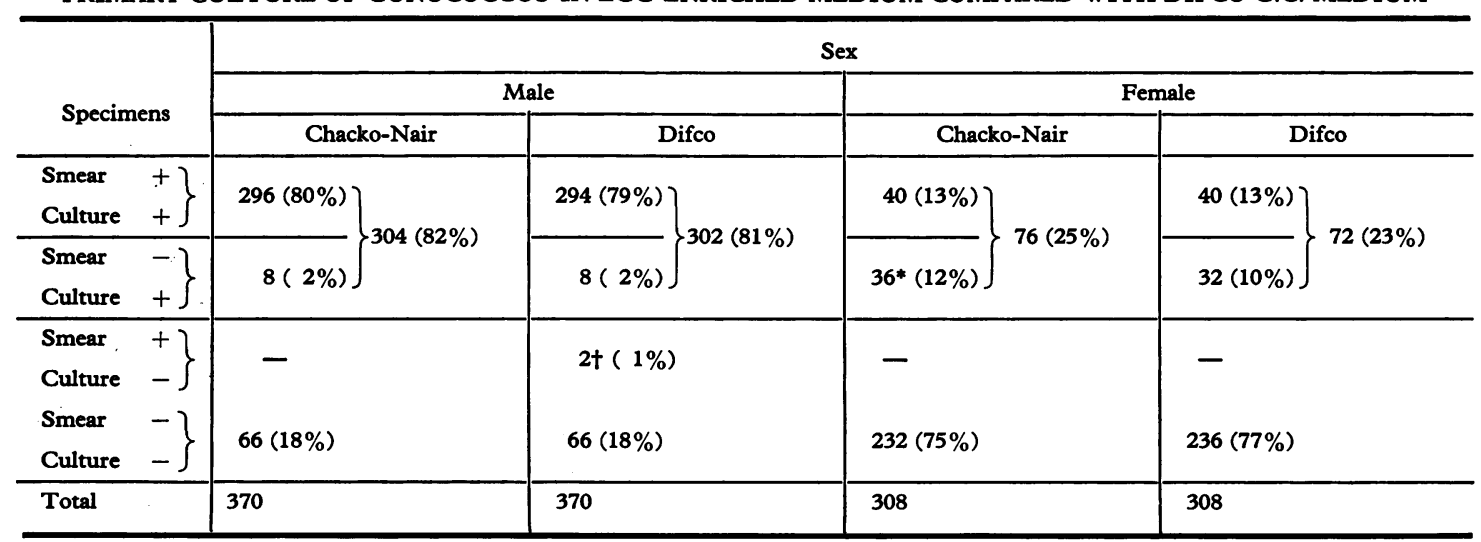

* These include one case of blennorrhoea in a young girl, eleven known asymptomatic contacts of gonorrhoea, fourteen asymptomatic carriers, and ten cases of vaginal discharge.

t From the specimen of urine and urethral discharge gonococci failed to grow in Difco medium. 
considered to reflect a fair sensitivity of the egg-enriched medium which may thus be used for the cultural diagnosis of gonorrhoea; eight ( 2 per cent.) of the 370 cases would have been missed by the smear method alone.

In specimens from 308 women suspected of having gonorrhoea on clinical grounds, gonococci were found in stained smears of urethral, cervical, or vaginal secretions and were grown on both media in forty cases (13 per cent.). A further 36 (12 per cent.) positive cultures on egg-enriched medium, of which 32 were also positive on Difco medium, were obtained from patients whose smears were negative. The total of 25 per cent. positive cultures obtained in this group may seem low, but many of these cases of vaginal discharge may not have been gonococcal in origin.

Eleven of 36 women from whom gonococci were cultured on both media were asymptomatic contacts of men with gonorrhoea.

Additionally, there was one case of blennorrhoea in a young girl. Fourteen other women from whom gonococci were grown on Chacko-Nair medium, ten giving positive results on Difco medium, seemed to be asymptomatic chronic female carriers, whose male contacts could not be traced. The remaining ten patients were suffering from vaginal discharge and repeated examinations of smears from the urethra, vagina and cervix did not reveal Gramnegative diplococci resembling gonococci.

Table II gives the results of the epidemiological study conducted for the detection of gonococcal carriers, who are potential sources of the spread and maintenance of gonorrhoea in a particular population group. Gonococci were isolated in culture from the urethra or urine on the test medium in 28 (61 per cent.) of 46 male cases examined. This suggested the possible importance of gonococcal infection in cases of urethritis in males who may carry it unrecognized as a source of infection in the community.

Out of 79 women attending the out-patients clinic who were investigated at random in this study and had apparently no particular complaint of white discharge, gonococci were isolated in culture in nine (11 per cent.) on the egg-enriched medium under evaluation. Only in three of the 79 cases where the culture was positive could Gram-negative diplococci resembling $N$. gonorrhoeae be demonstrated in smears. Of 146 specimens examined from female ante-natal cases checked at random, $N$. gonorrhoeae was isolated in culture on the test medium in two instances. Out of 100 cases examined from the gynaecological department, gonococci were grown in culture in six instances. These results suggest that the egg-enriched medium is of use in the investigation of gonorrhoea in the female.

Table III (overleaf) shows the results of the investigation of nasopharyngeal swabs from children attending the hospital for various respiratory infections by using smears and culture on the eggenriched medium devised for the gonococcus. Of 213 specimens examined by the direct smear method, 129 showed Gram-negative diplococci resembling Neisseriae, but on culture, only 32 were found to grow on the selective egg-enriched medium. These were finally identified as $N$. meningitidis by their ability to ferment glucose and maltose. It is considered possible that the other 92 strains of "Gramnegative diplococci" would also have grown on this egg-enriched medium had it not been made "selective" with antibiotics. It is reasonable to assume that all others were non-pathogens, possibly $N$. catarrhalis, $N$. sicca, $N$. flava, since they have been observed in this study to grow on the egg-enriched medium without the addition of Polymyxin B. Thus 32 (15 per cent.) of 213 cases surveyed were carriers of the meningococcus with the potentiality of causing

TABLE II

EPIDEMIOLOGICAL STUDY OF GONOCOCCAL INFECTION IN SELECTED POPULATIONS USING EGG-ENRICHED MEDIUM

\begin{tabular}{|c|c|c|c|c|c|c|c|}
\hline \multicolumn{2}{|c|}{ Source } & $\underset{\text { Smear }}{+}$ & $\underset{\text { Smear }}{-}$ & Smear + & Smear - & Total & Per cent. \\
\hline V.D. Clinic & $\begin{array}{c}\text { Male } \\
\text { Female }\end{array}$ & 28 & $\frac{-}{6}$ & 二 & $\begin{array}{l}18 \\
69\end{array}$ & $\begin{array}{l}46 \\
79\end{array}$ & $\begin{array}{l}61 \\
13\end{array}$ \\
\hline $\begin{array}{l}\text { Women and } \\
\text { Children's } \\
\text { Hospital, } \\
\text { Madras }\end{array}$ & $\begin{array}{c}\text { Ante-natal } \\
\text { Gynaecological }\end{array}$ & $\overline{1}$ & $\begin{array}{l}2 \\
5\end{array}$ & 二 & $\begin{array}{r}144 \\
94\end{array}$ & $\begin{array}{l}146 t \\
100 \ddagger\end{array}$ & $\begin{array}{l}1 \\
6\end{array}$ \\
\hline \multicolumn{2}{|c|}{ Total } & 33 & 13 & - & 325 & 371 & 12 \\
\hline
\end{tabular}

* One case of ophthalmia neonatorum.

+ VDRL test reactive in four specimens.

‡ VDRL test reactive in eight specimens. 
TABLE III

EPIDEMIOLOGICAL STUDY OF MENINGOCOCCAL INFECTION USING CHACKO-NAIR EGG-ENRICHED SELECTIVE MEDIUM DIRECT SMEAR EXAMINATION OF NASOPHARYNGEAL SWABS COMPARED WITH CULTURAL IDENTIFICATION OF N. MENINGITIDIS

\begin{tabular}{|c|c|c|c|c|c|c|c|c|c|c|}
\hline \multirow{2}{*}{\multicolumn{2}{|c|}{$\begin{array}{l}\text { Gram-negative } \\
\text { diplococci } \\
\text { in Smear and } \\
\text { Culture }\end{array}$}} & \multirow[b]{2}{*}{$\begin{array}{l}\text { No. } \\
\text { of } \\
\text { Cases }\end{array}$} & \multicolumn{8}{|c|}{ Organisms seen in Smears Only } \\
\hline & & & $\underset{\text { Group }}{\text { Haemophilus }}$ & $\begin{array}{c}\text { Klebsiella } \\
\text { Group }\end{array}$ & $\begin{array}{c}\text { Unidentified } \\
\text { Gram-negative } \\
\text { bacilli }\end{array}$ & $\begin{array}{c}\text { Fusiform } \\
\text { bacilli } \\
\text { and } \\
\text { Vincents' } \\
\text { spirochaetes }\end{array}$ & $\begin{array}{c}\text { Streptococci } \\
\text { including } \\
\text { Pneumo- } \\
\text { cocci }\end{array}$ & $\begin{array}{l}\text { Staphylo- } \\
\text { cocci }\end{array}$ & $\begin{array}{c}\text { Diph- } \\
\text { theroids }\end{array}$ & $\begin{array}{c}\text { Uniden- } \\
\text { tified }\end{array}$ \\
\hline $\begin{array}{l}\text { Smear } \\
\text { Culture }\end{array}$ & $\begin{array}{l}+ \\
+\end{array}$ & $\begin{array}{l}32 \\
(15 \%)\end{array}$ & 5 & 6 & 13 & 4 & 7 & 9 & 2 & 3 \\
\hline $\begin{array}{l}\text { Smear } \\
\text { Culture }\end{array}$ & + & 97 & 12 & 20 & 17 & 10 & 32 & 14 & 10 & 3 \\
\hline $\begin{array}{l}\text { Smear } \\
\text { Culture }\end{array}$ & $\overline{+}$ & 一 & - & - & - & - & - & - & - & - \\
\hline $\begin{array}{l}\text { Smear } \\
\text { Culture }\end{array}$ & $\overline{-}$ & 84 & 15 & 10 & 45 & 8 & 36 & 31 & 3 & 5 \\
\hline Total & & 213 & 32 & 36 & 75 & 22 & 75 & 54 & 15 & 11 \\
\hline
\end{tabular}

an epidemic of meningococcal infection in the population under favourable environmental condition.

Table III also shows that, in all cases in which the smears did not reveal Gram-negative diplococci, the culture was also negative. This suggested the possibility that, in the cultural investigation of nasopharyngeal swabs on this selective egg-enriched medium, a presumptive diagnosis of the meningococcal carrier condition could be made in 24 hours. The medium might also be used to isolate meningococci from the cerebrospinal fluid of suspected cases.

Furthermore, Table III shows that a number of other organisms commonly occurring in the throat were found in the smears along with $N$. meningitidis, but only the latter grew on the selective medium. Gram-negative diplococci predominated in smears in three instances only out of 129. In the other cases the predominant organisms were not Gramnegative diplococci. Even though Gram-negative diplococci were present in only a few smears, the medium was sensitive enough to support their growth in many more instances. The selective nature of the medium obviously allowed $N$. meningitidis to grow in culture in 32 instances in spite of the presence of Gram-negative bacilli in the smears; these organisms are able to overgrow the more fastidious meningococcus in culture.

Similarly, if the medium had not contained Mycostatin, cultural isolation of the meningococcus would have been difficult in at least three instances where fungi were seen in direct smears. Grampositive organisms, such as diphtheroids, staphylococci, and streptococci, which may cause diagnostic confusion with the gonococcus in cultures, could also possibly have been suppressed by the addition of the antibiotics Ristocetin or Vancomycin, which were not available to us. Either could well be included in the selective medium with suppressive effect on Gram-positive organisms, as reported by Thayer and Martin (1966).

In 97 instances, though smears from nasopharyngeal swabs had shown Gram-negative diplococci, these failed to grow on the medium. This is not thought to be due to the low sensitivity of the medium, but to the specific inhibitory effect of Polymyxin B on the non-pathogenic Neisseriae, which the organisms seen may have been.

The egg-enriched medium has been found useful for the maintenance of stock cultures of the pathogenic Neisseriae. Cultures of both gonococci and meningococci remained viable at $37^{\circ} \mathrm{C}$. for 7 to 10 days. It has also been found suitable for determining the sensitivity of gonococci to penicillin. Freezedried cultures of the Neisseriae group have been easily revived and maintained on this medium.

Thayer and Martin (1964) incorporated the antibiotics Ristocetin and Polymyxin B in Difco Bacto-haemoglobin yeast concentrate G.C. medium, to make it selective for the cultural diagnosis of $N$. gonorrhoeae. This selective medium inhibited non-pathogenic Neisseriae, Mima polymorpha, and other Gram-negative and Gram-positive organisms which usually overgrow the pathogenic Neisseriae in cultures from genito-urinary and nasopharyngeal specimens. It was also found in this study that $N$. catarrhalis, $N$. sicca, and $N$. flava did not grow on the egg-enriched medium made selective with Polymyxin B at a concentration of 25 units per ml., when kept at $37^{\circ} \mathrm{C}$. under $\mathrm{CO}_{2}$ for 5 days. It was also noted that Ps. aeruginosa, B. proteus, and paracolon bacilli are also inhibited by Polymyxin $B$. Diphtheroids and Gram-positive cocci grew on this medium and caused difficulty; Ristocetin, had it been available, might have overcome this. 
Ristocetin has been withdrawn from the market but can be replaced with Vancomycin. Thayer and Martin (1966) have reported improved results by the use of the antibiotics Vancomycin sulphate (Eli Lilly) 3 units per ml. to suppress Gram-positive contaminants and Colistimethate sodium (WarnerChilcot) $7.5 \mathrm{mg} . / \mathrm{ml}$. to inhibit Gram-negative bacterial flora, and Nystatin (Squibb) 12.5 units per $\mathrm{ml}$. to inhibit yeasts and to make the Difco medium more selective. It is expected that the egg-enriched medium, made similarly selective with this new combination of antibiotics, would be equally effective in this field.

It has been interesting to observe that for some time now meningococcal meningitis has not been diagnosed at all at the Madras General Hospital. This may be due either to the suppression of meningococcal meningitis by routine effective treatment or to the lack of adequate laboratory methods and particularly of a sensitive, simple, and convenient medium for the cultural isolation of the meningococcus from cerebrospinal fluid. In this connexion, the isolation of meningococci from nasopharyngeal material on the egg-enriched selective medium from 32 or 15 per cent. of 213 children attending the out-patients department of the Madras General Hospital has been interesting. This medium appears suitable for routine use in attempts to isolate $N$. meningitidis from the cerebrospinal fluid of cases of meningitis. The results of this study seem to show that meningococci are present in a significant number of children in Madras who may be acting as carriers and be the potential source of endemic or epidemic infection of meningococcal meningitis.

\section{Summary}

The results of a more extensive evaluation of the Chacko-Nair medium enriched with hen's egg contents and made selective with Polymyxin B and Mycostatin, for the artificial culture of the pathogenic Neisseria group of organisms are reported. This medium supported the primary isolation and growth of 426 local strains of $N$. gonorrhoeae. In a comparative evaluation of this egg-enriched medium, it was found to be at least as effective as the Difco G.C. medium in conventional use in the cultural diagnosis of gonorrhoea in infected men and women. In addition, it is easy and convenient to prepare in any bacteriological laboratory, and may also be used in the epidemiological investigation of $N$. meningitidis.

The Governments of India and Madras provided all facilities for research in this field at the Central V.D. Reference Laboratory at Madras. This work has been encouraged by the provision of special equipment and reagents by the W.H.O.

The authors are grateful to Dr P. N. Rangiah, Director, and Dr Sowmini, Associate Professor, of the Madras Institute of Venereology, to Dr M. K. K. Menon, Director, and Dr Nabeesa Bee, of the Madras Institute of Gynaecology and Obstetrics, and Dr Balagopala Raju, Director, and Dr R. Chacko, of the Madras Institute of Paediatrics, for their willing co-operation and provision of clinical materials for this study.

\section{REFERENCES}

Chacko, C. W., and Nair, G. M. (1966). Indian F. Derm., 32, 41; WHO/VDT/RES/GON/66.12.

Thayer, J. D., and Martin, J. E. (1964). Publ. Hlth Rep. (Wash.), 79, 49.

—— (1966). Ibid., 81, 559.

Le milieu sélectif Chacko-Nair enrichi par l'œuf dans le diagnostic des Neisseriae pathogéniques

\section{RÉsUMÉ}

Les résultats d'une plus grande évaluation du milieu Chacko-Nair enrichi par l'œuf de poule et rendu sélecteur par l'addition de la Polymyxine B et de la Mysostatine pour la culture artificielle des diplocoques pathogéniques du groupe Neisseria sont rapportées. Ce milieu a permis la séparation initiale de 426 souches locales de $N$. gonorrhoeae. Dans une évaluation comparative de ce milieu enrichi par l'œuf, il a été trouvé qu'il était au moins aussi effectif que le milieu Difco G.C. dans l'usage courant du diagnostic de la blennorragie par culture chez les hommes et les femmes atteints de cette maladie. De plus, il est facile et commode de le préparer dans n'importe quel laboratoire bactériologique et il peut aussi servir dans les recherches épidémiologiques du $N$. meningitidis. 